\title{
ChemComm
}

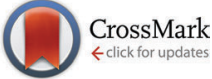

Cite this: Chem. Commun., 2016, 52,13869

Received 12th October 2016, Accepted 7th November 2016

DOI: $10.1039 / c 6 c c 08226 b$

www.rsc.org/chemcomm

\section{Mirror symmetry breaking in cubic phases and isotropic liquids driven by hydrogen bonding $\dagger$}

\author{
Mohamed Alaasar, ${ }^{\text {ab }}$ Silvio Poppe, ${ }^{a}$ Qingshu Dong, ${ }^{c}$ Feng Liu ${ }^{\star c}$ and \\ Carsten Tschierske*a
}

\begin{abstract}
Achiral supramolecular hydrogen bonded complexes between rodlike 4-(4-alkoxyphenylazo)pyridines and a taper shaped 4-substituted benzoic acid form achiral $(I a \overline{3} d)$ and chiral "Im $m \overline{3} m$-type" bicontinuous cubic (1432) phases and a chiral isotropic liquid mesophase ( $\left(\mathrm{so}_{1}{ }^{[*]}\right)$. The chiral phases, resulting from spontaneous mirror symmetry breaking, represent conglomerates of macroscopic chiral domains eventually leading to uniform chirality.
\end{abstract}

Mirror symmetry breaking in liquid crystalline (LC) and liquid phases of achiral molecules is of significant interest as it provides an efficient way to spontaneous chirogenesis in fluids, thus being of potential importance for the emergence of biochirality as well as providing a new way to produce chiral materials. ${ }^{1}$ For example conglomerates of chiral domains were formed by achiral bentcore molecules in the optically isotropic dark-conglomerate (DC) phases $^{2,3}$ as well as in birefringent SmC phases ${ }^{4}$ and nematic phases. ${ }^{5}$ Twist bend nematic phases $\left(\mathrm{N}_{\mathrm{TB}}\right)$ represent another type of mirror symmetry broken fluids formed by bent-core mesogens, ${ }^{6}$ rod-like dimesogens, ${ }^{7}$ trimesogens ${ }^{8}$ and main chain polymers. ${ }^{9}$ Recently, mirror symmetry breaking with formation of chiral conglomerates was even observed in $\operatorname{Im} \overline{3} m$-type bicontinuous cubic phases ${ }^{10}$ and in isotropic liquids (Iso $\left.{ }^{[*]}\right)^{11}$ of achiral rodlike multi-chain (polycatenar) molecules. ${ }^{1,12} \mathrm{~A}$ twisted organization of the molecules in the column segments of the branched networks forming these cubic phases and in the local cybotactic domains of the isotropic liquids is assumed to couple cooperatively with helical conformers of the transiently chiral molecules, leading to the development of macroscopic chirality. ${ }^{1,10,11}$ This dynamic mode of mirror symmetry breaking in the liquid state retains high entropy and allows fast reversible chiral segregation in

\footnotetext{
${ }^{a}$ Institute of Chemistry, Martin Luther University Halle-Wittenberg, Kurt-Mothes Str.2, D-06120 Halle, Germany. E-mail: carsten.tschierske@chemie.uni-halle.de

${ }^{b}$ Department of Chemistry, Faculty of Science, Cairo University, Giza, Egypt.

E-mail:malaasar@sci.cu.edu.eg

${ }^{c}$ State Key Laboratory for Mechanical Behavior of Materials,

Xi'an Jiaotong University, Xi'an 710049, P. R. China. E-mail: feng.liu@xjtu.edu.cn

$\dagger$ Electronic supplementary information (ESI) available: Synthesis, analytical data, additional data. See DOI: $10.1039 / \mathrm{c} 6 \mathrm{cc} 08226 \mathrm{~b}$
}

the presence of relatively weak intermolecular interactions. In order to minimize the unfavourable entropy of mixing, relatively large molecules are required for this process. An efficient way to achieve larger supramolecular units is provided by self assembly of smaller molecules by noncovalent interactions, such as hydrogen bonding, halogen bonding and $\pi$-stacking.

Hydrogen-bonding, especially between pyridines and benzoic acids was previously used to design nematic, smectic and columnar mesomorphic materials ${ }^{13-16}$ whereas cubic LC phases formed by discrete self assembly between two or three components are rare.f The first examples of bicontinuous cubic phases formed through discrete intermolecular hydrogen bonding interaction is provided by the $4^{\prime}-n$-alkoxy-3'-nitrobiphenyl-4-carboxylic acids. ${ }^{17}$ Cubic phases were also reported for supramolecular systems constructed by self-assembly through intermolecular hydrogenbond formation between 4,4'-bipyridines and 4-substituted benzoic acids with bulky siloxane moieties ${ }^{18 a}$ or branched perfluorinated chains. ${ }^{18 b}$ To the best of our knowledge there are no examples reported up to date for bicontinuous cubic phases formed by supramolecular hydrogen bonded polycatenar $\mathrm{LCs}^{12}$ and spontaneous symmetry breaking has not yet been reported for any supramolecular polycatenar mesogen.§

Herein we report for the first time how hydrogen bonding can be used to drive mirror-symmetry breaking in an isotropic liquid as well as in cubic phases of supramolecular tetracatenar complexes (AB8-AB14) between rod-like 4-phenylazopyridines $\mathbf{B} \boldsymbol{n}^{19,20}$ with one terminal alkoxy chain and the benzoic acid $\mathbf{A}$, having three identical terminal alkoxy chains (Scheme 1). $\uparrow$ The azopyridines $\mathbf{B} \boldsymbol{n}^{20 b}$ and the benzoic acid derivative $\mathbf{A}$ were synthesized through the synthetic pathway shown in Scheme 1. The detailed synthetic procedures and analytical data are reported in the ESI. $\dagger$

The 4-(4-alkyloxyphenylazo)pyridines $\mathbf{B} \boldsymbol{n}$ represent nonmesomorphic solids which directly melt to isotropic liquids between 66 and $74{ }^{\circ} \mathrm{C}$ (Table S1, ESI $\dagger$ ). ${ }^{20 b}$ The benzoic acid A exhibits a hexagonal columnar LC phase ( $\left.\mathrm{Col}_{\text {hex }}\right)$ between 162 and $246{ }^{\circ} \mathrm{C}$ as indicated by X-ray diffraction (XRD, $a_{\text {hex }}=5.4 \mathrm{~nm}$ see Fig. S9 and Table S2, ESI $\dagger$ ), in line with the birefringent 


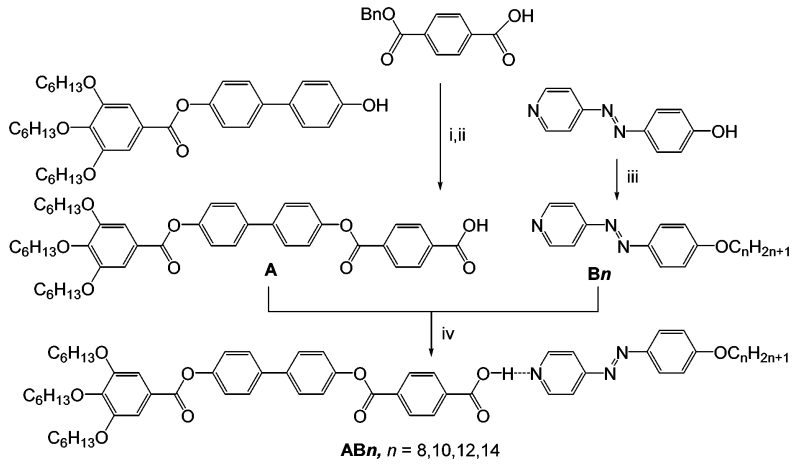

Scheme 1 Synthetic route to the pyridines $\mathbf{B n}^{20 b}$ and the benzoic acid $\mathbf{A}$ and formation of the polycatenar hydrogen-bonded complexes $\mathbf{A B n}$. Reagents and conditions: (i) DCC, DMAP, DCM, stirring, rt, $48 \mathrm{~h}$; (ii) $10 \%-\mathrm{Pd} / \mathrm{C}, \mathrm{H}_{2}$, stirring, $45^{\circ} \mathrm{C}$, $48 \mathrm{~h}$; (iii) $\mathrm{BrC}_{n} \mathrm{H}_{2 n+1}, \mathrm{Kl}, \mathrm{K}_{2} \mathrm{CO}_{3}, \mathrm{DMF}$, stirring, $50{ }^{\circ} \mathrm{C}, 48 \mathrm{~h}$; (iv) melting with stirring.

fan-like texture observed under the polarizing microscope (PM, Fig. S6a, ESI $\dagger$ ). The observation of a $\mathrm{Col}_{\text {hex }}$ phase for $\mathbf{A}$ is attributed to dimer formation by intermolecular H-bonding between the $\mathrm{COOH}$ groups, leading to hexacatenar rod-like complexes which arrange side by side and on top of each other thus forming columns being rotationally disordered and arranged on a hexagonal lattice. In the columns the rod-like cores are aligned almost perpendicular to the column long axis, resulting in an optically negative $\mathrm{Col}_{\text {hex }}$ phase (Fig. S6b and c, ESI†), as typical for hexacatenars. ${ }^{12}$ The supramolecular aggregates AB8-AB14 were prepared by mixing equimolar amounts of $\mathbf{B} \boldsymbol{n}$ and $\mathbf{A}$ and then melting them together in DSC pans (30 $\mu$ l) with stirring. After crystallization the material was grinded, and this process was repeated to obtain a homogeneous mixture.

Homogenous melting and reproducible transition temperatures were observed for all supramolecular complexes $\mathbf{A B n}$. The formation of the supramolecular 1:1 complexes between the benzoic acid $\mathbf{A}$ and the 4-phenylazopyridines $\mathbf{B} \boldsymbol{n}$ (for ${ }^{1} \mathrm{H}$-NMR, see Fig. S4, ESI $\dagger$ ) leads to the suppression of the columnar phase and induction of broad cubic LC phase ranges for all hydrogen bonded complexes as determined by differential scanning calorimetry (DSC, see Fig. 1; the intense peaks of the

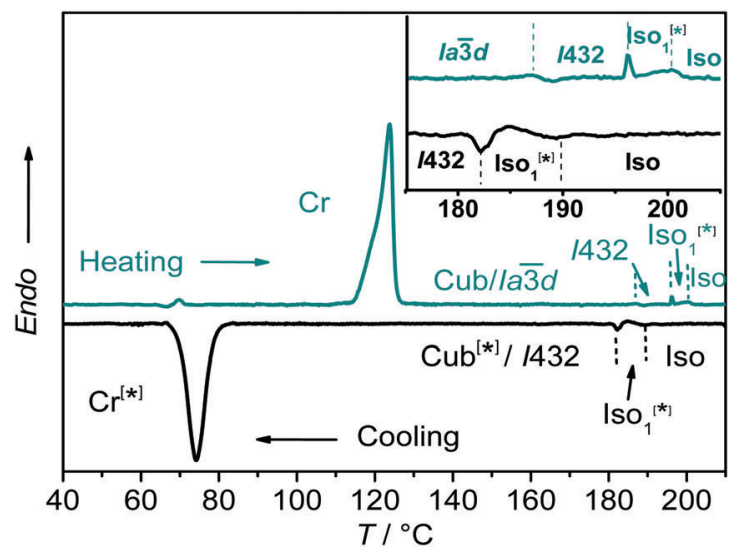

Fig. 1 DSC heating and cooling traces $\left(10 \mathrm{~K} \mathrm{~min}^{-1}\right)$ observed for the complex AB8. The inset shows the heating and cooling traces for the temperature range of the Iso-Iso ${ }^{[*]}-\mathrm{Cub}^{[*]} / / 432$ transitions between $175^{\circ} \mathrm{C}$ and $205^{\circ} \mathrm{C}$.
Table 1 Phase transition temperatures $\left(T /{ }^{\circ} \mathrm{C}\right)$, mesophase types, and transition enthalpies $\left[\Delta H / \mathrm{J} \mathrm{g}^{-1}\right]$ of the supramolecular complexes $\mathbf{A B} \boldsymbol{n}^{a}$

\begin{tabular}{|c|c|c|}
\hline No. & $n$ & Phase sequence \\
\hline AB8 & 8 & $\begin{array}{l}\mathrm{H}: \mathrm{Cr} 124[28] \mathrm{Ia} \overline{3} d \sim 187[0.1] \mathrm{I} 432196[0.1] \\
\mathrm{Iso}_{1}^{[*]} 200[0.1] \text { Iso } \\
\text { C: Iso } 190[0.1] \text { Iso }_{1}^{[*]} 183[0.1] \text { I4t32 } 75[23] \mathrm{Cr}^{[*]}\end{array}$ \\
\hline AB10 & 10 & $\begin{array}{l}\mathrm{H}: \mathrm{Cr}_{1} 115[11] \mathrm{Cr}_{2} 128[41] \mathrm{I} / 32201[0.8] \text { Iso } \\
\text { C: Iso } 195[0.7] \mathrm{I} 43275[35] \mathrm{Cr}\end{array}$ \\
\hline AB12 & 12 & $\begin{array}{l}\text { H: Cr } 123[48] \text { I432 } 191[1.2] \text { Iso } \\
\text { C: Iso } 182[1.7] \text { I432 } 87[40] \mathrm{Cr}\end{array}$ \\
\hline AB14 & 14 & $\begin{array}{l}\text { H: Cr } 92[27] \text { I I432 } 184[1.7] \text { Iso } \\
\text { C: Iso } 177[1.8] \text { I432 }\end{array}$ \\
\hline
\end{tabular}

${ }^{a}$ Peak temperatures as determined from 1 st heating $(\mathrm{H})$ and 1 st cooling $(\mathrm{C})$ DSC scans with rate $10 \mathrm{~K} \mathrm{~min}^{-1}$; abbreviations: $\mathrm{Cr}=$ crystalline solid; I432 = chiral "I $\overline{3} \overline{3} m$-type" cubic LC phase with $I 432$ symmetry; $I a \overline{3} d=$ achiral cubic LC phase with Ia $\overline{3} d$ symmetry; $\mathrm{Cr}^{[*]}=$ chiral crystalline solid; $\mathrm{Iso}_{1}{ }^{[*]}=$ chiral isotropic conglomerate liquid; Iso = achiral isotropic liquid.

individual components, see Fig. S5, are absent, ESI $\dagger$ ), PM and XRD investigations (see Table 1).

Exclusively cubic phases were found for the complexes AB10AB14, whereas for the 1:1 complex $\mathbf{A B 8}$ an addition liquid-liquid transition is indicated in the DSC traces by a broad feature in the isotropic liquid range (Iso-Iso ${ }_{1}$ transition, Fig. 1). Between crossed polarizers the liquid phases Iso as well as $\mathrm{Iso}_{1}$ appear uniformly dark. However, in the Iso $_{1}$ phase range slightly rotating the analyzer by a few degrees $\left(\mathrm{ca} .-7^{\circ}\right)$ out of the $90^{\circ}$ orientation with respect to the polarizer leads to the appearance of dark and bright domains, which exchange their brightness after rotation of the analyzer by the same angle into the opposite direction ( $c a .+7^{\circ}$, see Fig. $2 \mathrm{a}$ and b). Rotating the sample between crossed polarizers does not lead to any change and these observations confirm that the distinct regions represent chiral domains. This is a clear indication for chirality synchronization in the $\mathrm{IsO}_{1}$ phase $\left(\mathrm{Iso}_{1}{ }^{[*]}\right)$. No such domains can be observed in the Iso phase of $\mathbf{A B 8}$ at higher temperature or in the Iso phases of complexes AB10-AB14, which are achiral.
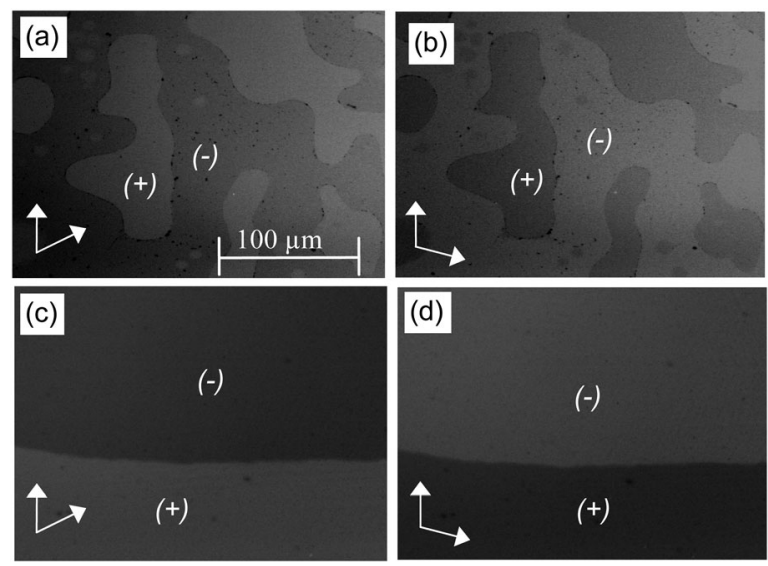

Fig. 2 Textures of the complex $\mathbf{A B 8}$ on cooling from the isotropic liquid (Iso): (a and b) in Iso ${ }_{1}^{[*]}$ liquid at $T=188^{\circ} \mathrm{C}$ and ( $\mathrm{c}$ and d) in the $\mathrm{Cub}{ }^{[*]} / / 432$ LC phase at $T=150{ }^{\circ} \mathrm{C}$ on further cooling, (a and c) after rotating one polarizer from the crossed position by $7^{\circ}$ in anticlockwise direction and (b and d) in clockwise direction, showing dark and bright domains, indicating the presence of areas with opposite chirality sense; the dark spots are aluminium particles resulting from the vigorous stirring in the DSC pans. 
(a)

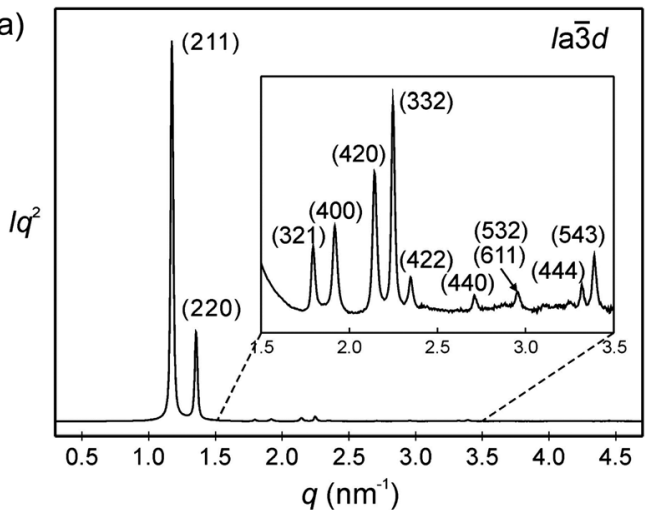

(b)

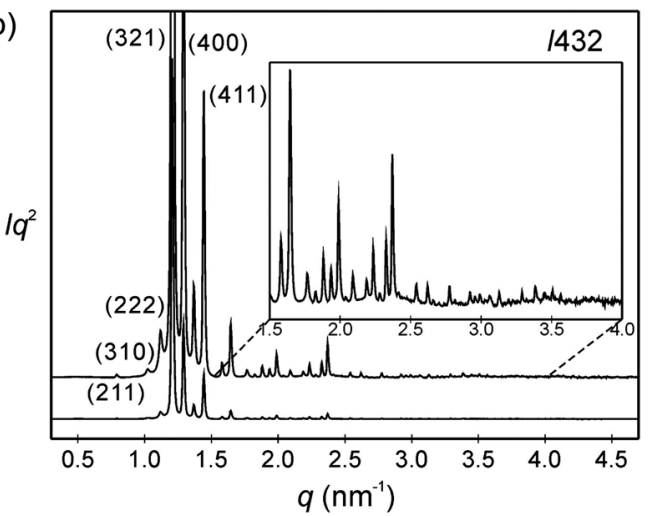

Fig. 3 SAXS diffractograms of (a) the Cub//a $\overline{3} d$ phase $\left(a_{\text {cub }}=13.10 \mathrm{~nm}\right)$ of AB8, recorded at $T=150{ }^{\circ} \mathrm{C}$ on heating (for wide angle scattering see Fig. S10b, ESI $)$; (b) the $\mathrm{Cub}^{[*]} / / 432$ phase $\left(a_{\text {cub }}=19.46 \mathrm{~nm}\right)$ of $\mathbf{A B 1 4}$ at $T=140{ }^{\circ} \mathrm{C}$, the curve on top is enhanced by a factor of 7 and only some diffractions at lower angles are labelled; see also Tables S3-S6 (ESI†).

The transition to the cubic phase is indicated by a small, but relatively sharp peak in the DSC traces (Fig. 1). The transition enthalpy of this transition rises with growing chain length from 0.1 to $1.8 \mathrm{~J} \mathrm{~g}^{-1}$ (Table 1). As typical for mesophases with long range 3D lattice there is a hysteresis of this transition to the cubic phase on

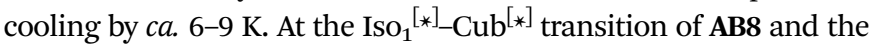
Iso-Cub $^{[*]}$ transitions of the complexes AB10-AB14 the samples remain optically isotropic, but these transitions are associated with a significant reduction of the fluidity leading to soft viscoelastic solids. The diffuse scattering in the wide angle range of the XRD patterns is retained (Fig. S10b, ESI $\dagger$ ) indicating the absence of a long range positional order of the individual molecule as typical for LC phases. In the case of $\mathbf{A B 8}$ the chiral domains in the $\mathrm{IsO}_{1}{ }^{[*]}$ phase grow to huge homogeneously chiral domains of either handedness, even across the original chiral domain boundaries (see Fig. 2c and d). The complexes AB10-AB14 form the chiral domains directly at the transition from the achiral Iso phase to the $\mathrm{Cub}^{[*]}$ phases. Also for these complexes large chiral domains are formed (Fig. S8, ESI $\dagger$ ) and on very slow cooling $\left(<1 \mathrm{~K} \mathrm{~min}^{-1}\right)$ it is even possible to achieve uniform chirality, indicating slow formation of the seeds of the cubic phase combined with a fast growth; the distribution of either chirality sense is stochastic.

The powder XRD patterns of the cubic conglomerate phases of the supramolecules $\mathbf{A B} \boldsymbol{n}$ (Fig. 3b and Fig. S10, ESI $\dagger$ ) can be indexed to $\operatorname{Im} \overline{3} m$ lattices with nearly chain length independent lattice
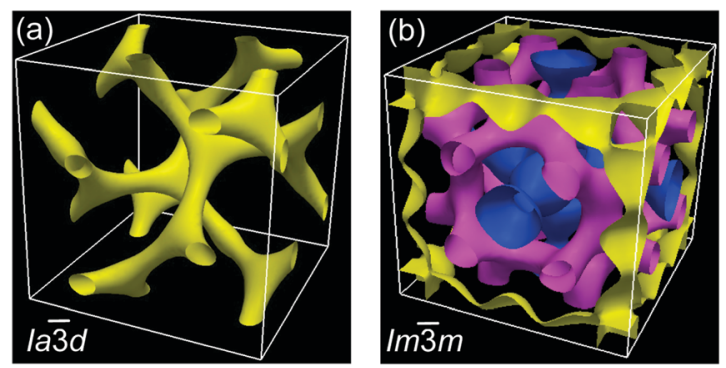

Fig. 4 Reconstructed EDMs: (a) of a unit cell of the Cub/la $\overline{3} d$ phase of AB8 only showing the high density regions and (b) of the $I m \overline{3} m$ approximate of the $\mathrm{Cub}^{[*]} / / 432$ phase of AB14 showing the three distinct iso-surfaces with different colour.

parameters $\left(a_{\text {cub }}=19.4-19.5 \mathrm{~nm}\right.$, see Tables S4-S6, ESI $\left.\dagger\right)$. Based on this phase assignment the electron density map (EDM) of AB14 was reconstructed from the powder diffraction pattern, showing a tricontinuous structure of this cubic phase (Fig. $4 \mathrm{~b}$ ). It should be noted here that due to the chirality the actual space group is a chiral one, that with the highest symmetry being I432. However as the phase angle can represent any value between 0 and $\pm \pi$ in this non-centrosymmetric lattice we assume the centrosymmetric $\operatorname{Im} \overline{3} m$ structure as a close approximate for electron density reconstruction, limiting the phase choices to 0 and $\pm \pi$. The three interwoven but not connected high electron density networks (yellow, purple and blue in Fig. 4b, respectively) involve the hydrogen bonded aromatic cores arranged with their long axes perpendicular to the directions of the column segments forming the labyrinths. Due to the steric crowding of the alkyl chains at the ends the organization of the rods is not exactly parallel, but with a slight angle leading to a helical twist along the networks. ${ }^{10,21}$ The network structure leads to a long range transmission of the helix sense once formed and exciton coupling between the twisted $\pi$-systems is assumed to mainly contribute to optical rotation. ${ }^{22}$ As there are three networks, chirality cannot be cancelled even if the helix sense would be opposite in adjacent networks. The space between the networks is filled by the disordered alkyl chains.

Only the supramolecular complex AB8 exhibits an additional cubic phase which is achiral based on optical investigations (uncrossing the polarizers by a small angle in clockwise or anticlockwise direction does not lead to any change). The diffraction pattern in the achiral cubic phase (Fig. 3a) can be indexed to a cubic lattice with $I a \overline{3} d$ symmetry $\left(a_{\text {cub }}=13.10 \mathrm{~nm}\right.$, Table S3, ESI $\left.\dagger\right)$ and represents a gyroid-type bicontinuous double-network phase as shown in the reconstructed EDM in Fig. 4a. The two interwoven high electron density networks (yellow) are filled with the hydrogen bonded cores, being arranged perpendicular to the column segments of the networks and slightly twisted with respect to each other, thus forming only two helically twisted networks with opposite helix sense, cancelling each other to give an achiral structure. ${ }^{10}$ This achiral $I a \overline{3} d$ phase is formed on melting the crystalline phase (Cr) at $T=124{ }^{\circ} \mathrm{C}$ and on heating transforms into the chiral $I 432$ phase at $T=180-187{ }^{\circ} \mathrm{C}\left(a_{\mathrm{cub}}=19.53 \mathrm{~nm}\right)$ as indicated by optical investigations (appearance of chiral domains), DSC (small enthalpy of $0.1 \mathrm{~J} \mathrm{~g}^{-1}$ ) and from temperature dependent XRD studies by a change of the diffraction pattern (Table S4, ESI $\dagger$ ). This chiral cubic 
phase melts at $T=196{ }^{\circ} \mathrm{C}$ with the formation of the chiral $\mathrm{Iso}_{1}{ }^{[*]}$ phase which transforms into the achiral Iso phase at $T=200{ }^{\circ} \mathrm{C}$. On cooling AB8 from the Iso state $\mathrm{IsO}_{1}{ }^{[*]}$ is formed at $T=190{ }^{\circ} \mathrm{C}$, followed by the transition to the chiral $\mathrm{Cub}^{[*]}$ phase (I432) at $T=183{ }^{\circ} \mathrm{C}$ (Fig. 1 and Table 1 ). The chiral domains and the typical diffraction pattern of the 1432 phase are retained till the crystallization at $T=75{ }^{\circ} \mathrm{C}$. Interestingly, the crystalline state of AB8 exhibits also chiral domains as indicated by the textural observations under PM (see Fig. S7, ESI $\dagger$ ), thus indicating crystallization in a chiral space group $\left(\mathrm{Cr}^{[*]}\right)$. Heating this $\mathrm{Cr}^{[*]}$ phase (which melts at $T=114{ }^{\circ} \mathrm{C}$ ) leads directly to the chiral I432 phase without intermediate formation of the achiral $I a \overline{3} d$ phase. Thus, the chirality once achieved is retained on crystallization and the formation of the $I a \overline{3} d$ phase is suppressed. The $I a \overline{3} d$ phase is only obtained after heating the crystalline sample after prolonged storage. It appears that the (metastable) $\mathrm{Cr}^{[*]}$ phase slowly transforms into an achiral crystalline phase $\left(\mathrm{Cr}, \mathrm{m} . \mathrm{p} .=124{ }^{\circ} \mathrm{C}\right)$ from which the achiral $I a \overline{3} d$ phase is formed on heating. This means that the cubic 1432 phase is metastable below $187{ }^{\circ} \mathrm{C}$, but once formed seems to be persistent. The transition $I a \overline{3} d-I 432$ observed in the series $\mathbf{A B n}$ on chain elongation and with rising temperature (AB8) is in line with the recently proposed helical model, as the effective chain volume increases with rising temperature and growing alkyl chain length and this reduces the helical pitch becoming incompatible with the $I a \overline{3} d$ structure and leading to formation of the $I 432$ cubic phase. ${ }^{10}$

In summary, we report herein the design and synthesis of the first examples of hydrogen bonded supramolecular complexes with polycatenar structure showing dynamic mirror-symmetry breaking by chirality synchronization in a liquid conglomerate $\left(\mathrm{Iso}_{1}{ }^{[*]}\right)$ at the liquid-liquid transition as well as in chiral "I $m \overline{3} m$-type" cubic phases $\left(\mathrm{Cub}^{[*]} / \mathrm{I} 432\right)$. The liquid conglomerate is obviously only formed if the alkyl chains are short and nano-segregation between alkyl chain and core unit is sufficiently weak to prevent formation of a long range cubic lattice. Overall, this work could initiate further work on using hydrogen bonding for symmetry breaking in fluids. Moreover, the possibilities provided by the photosensitive azobenzene units ${ }^{23}$ could lead to interesting perspectives for chirality switching and phase modulation by interaction with non-polarized and (linear or circular) polarized light. ${ }^{24}$

The work was funded by the DFG (Grant Ts 39/24-1) and the National Natural Science Foundation of China (No. 21374086). We thank Beamline BL16B1 at SSRF (Shanghai Synchrotron Radiation Facility, China) for providing the beamtimes.

\section{Notes and references}

\$ Multiple cooperative hydrogen bonding between amphiphilic glycerolbased or carbohydrate based molecules forming polymeric hydrogen bonding networks are more common. ${ }^{25}$

$\S$ Mirror symmetry breaking by hydrogen bonding in soft matter was previously reported for the $\mathrm{N}_{\mathrm{TB}}$ phases of hydrogen bonded mesogenic trimers $^{24}$ and the cubic phase of a bent molecule. ${ }^{26}$

T The azopyridine derivatives $\mathbf{B} \boldsymbol{n}$ have previously been used for the formation of supramolecular self-assembled hydrogen bonded ${ }^{19}$ and halogen-bonded $\mathrm{LCs}^{20}$ with light induced phase transitions.

1 C. Tschierske and G. Ungar, ChemPhysChem, 2016, 17, 9.

2 (a) J. Thisayukta, Y. Nakayama, S. Kawauchi, H. Takezoe and J. Watanabe, J. Am. Chem. Soc., 2000, 122, 7441; (b) G. Dantlgraber,
A. Eremin, S. Diele, A. Hauser, H. Kresse, G. Pelzl and C. Tschierske, Angew. Chem., Int. Ed., 2002, 41, 2408; (c) L. E. Hough, M. Spannuth, M. Nakata, D. A. Coleman, C. D. Jones, G. Dantlgraber, C. Tschierske, J. Watanabe, E. Körblova, D. M. Walba, J. E. Maclennan, M. A. Glaser and N. A. Clark, Science, 2009, 325, 452; (d) H. Sasaki, Y. Takanishi, J. Yamamoto and A. Yoshizawa, J. Phys. Chem. B, 2015, 119, 4531.

3 H. Takezoe, Top. Curr. Chem., 2012, 318, 303.

4 (a) M. Alaasar, M. Prehm, M. Nagaraj, J. K. Vij and C. Tschierske, Adv. Mater., 2013, 25, 2186; (b) M. Alaasar, M. Prehm, K. May, A. Eremin and C. Tschierske, Adv. Funct. Mater., 2014, 24, 1703.

5 V. Görtz, Liq. Cryst. Today, 2010, 19, 37.

6 D. Chen, J. H. Porada, J. B. Hooper, A. Klittnick, Y. Shen, M. R. Tuchband, E. Körblova, D. Bedrov, D. M. Walba, M. A. Glaser, J. E. Maclennan and N. A. Clark, Proc. Natl. Acad. Sci. U. S. A., 2013, 110, 15931.

7 (a) V. Borshch, Y.-K. Kim, J. Xiang, M. Gao, A. Jakli, V. P. Panov, J. K. Vij, C. T. Imrie, M. G. Tamba, G. H. Mehl and O. D. Lavrentovich, Nat. Commun., 2013, 4, 2635; (b) M. Cestari, S. Diez-Berart, D. A. Dunmur, A. Ferrarini, M. R. de la Fuente, D. J. B. Jackson, D. O. Lopez, G. R. Luckhurst, M. A. Perez-Jubindo, R. M. Richardson, J. Salud, B. A. Timimi and H. Zimmermann, Phys. Rev. E: Stat., Nonlinear, Soft Matter Phys., 2011, 84, 031704; (c) R. J. Mandle, Soft Matter, 2016, 12, 7883.

8 (a) R. J. Mandle and J. W. Goodby, ChemPhysChem, 2016, 17, 967; (b) Y. Wang, Z. Zheng, H. K. Bisoyi, K. G. Gutierrez-Cuevas, L. Wang, R. S. Zolab and Q. Li, Mater. Horiz., 2016, 3, 442.

9 G. Ungar, V. Percec and M. Zuber, Macromolecules, 1992, 25, 75.

10 C. Dressel, F. Liu, M. Prehm, X. Zeng, G. Ungar and C. Tschierske, Angew. Chem., Int. Ed., 2014, 53, 13115.

11 (a) C. Dressel, T. Reppe, M. Prehm, M. Brautzsch and C. Tschierske, Nat. Chem., 2014, 6, 971; (b) M. Alaasar, M. Prehm, Y. Cao, F. Liu and C. Tschierske, Angew. Chem., Int. Ed., 2016, 55, 312; (c) C. Dressel, W. Weissflog and C. Tschierske, Chem. Commun., $2015, \mathbf{5 1}, 15850$.

12 W. Weissflog, in Handbook of Liquid Crystals, ed. J. W. Goodby, P. J. Collings, T. Kato, C. Tschierske, H. Gleeson and P. Raynes, Wiley-VCH, Weinheim, 2014, vol. 5, p. 89.

13 T. Kato and J. M. J. Frechet, J. Am. Chem. Soc., 1989, 111, 8533.

14 B. Friot, D. Boyd, K. Willis, B. Donnio, G. Ungar and D. W. Bruce, Liq. Cryst., 2000, 27, 605.

15 (a) C. M. Paleos and D. Tsiourvas, Liq. Cryst., 2001, 28, 1127; (b) T. Kato and Y. Kamikawa, in Handbook of Liquid Crystals, ed. J. W. Goodby, P. J. Collings, T. Kato, C. Tschierske, H. Gleeson and P. Raynes, Wiley-VCH, Weinheim, 2014, vol. 5, 513.

16 S. M. Jansze, A. Martinez-Felipe, J. M. D. Storey, A. T. M. Marcelis and C. T. Imrie, Angew. Chem., Int. Ed., 2015, 54, 643.

17 (a) G. W. Gray, B. Jones and F. Marson, J. Chem. Soc., 1957, 393; (b) D. Demus, G. Kunicke, J. Neelsen and H. Sackmann, Z. Naturforsch., A: Phys. Sci., 1968, 23, 84; (c) S. Kutsumizu, Isr. J. Chem., 2012, 52, 844 .

18 (a) E. Nishikawa and E. T. Samulski, Liq. Cryst., 2000, 27, 1463; (b) E. Nishikawa, J. Yamamoto and H. Yokoyama, Liq. Cryst., 2003, 30, 785 .

19 (a) J. Mamiya, A. Yoshitake, M. Kondo, Y. Yu and T. Ikeda, J. Mater. Chem., 2008, 18, 63; (b) K. Aoki, M. Nakagawa and K. Ichimura, J. Am. Chem. Soc., 2000, 122, 10997; (c) M. Pfletscher, C. Wölper, J. S. Gutmann, M. Mezger and M. Giese, Chem. Commun., 2016, 52, 8549.

20 (a) W. Zhou, T. Kobayashi, H. Zhu and H. F. Yu, Chem. Commun., 2011, 47, 12768; (b) Y. J. Chen, H. F. Yu, L. Y. Zhang, H. Yang and Y. F. Lu, Chem. Commun., 2014, 50, 9647.

21 K. Saito, Y. Yamamura, Y. Miwa and S. Kutsumizu, Phys. Chem. Chem. Phys., 2016, 18, 3280.

22 G. Pescitelli, L. Di Bari and N. Berova, Chem. Soc. Rev., 2014, 43, 5211.

23 H. M. D. Bandara and S. C. Burdette, Chem. Soc. Rev., 2012, 41, 1809.

24 D. A. Paterson, J. Xiang, G. Singh, R. Walker, D. M. Agra-Kooijman, A. Martınez-Felipe, M. Gao, J. M. D. Storey, S. Kumar, O. D. Lavrentovich and C. T. Imrie, J. Am. Chem. Soc., 2016, 138, 5283.

25 K. Borisch, S. Diele, P. Göring, H. Kresse and C. Tschierske, Angew. Chem., Int. Ed., 1997, 36, 2087.

26 T. Kajitani, S. Kohmoto, M. Yamamoto and K. Kishikawa, Chem. Mater., 2005, 17, 3812. 